стабилизации глюкозы в крови, а эта фармакотерапия не всегда сочетается с противокоронавирусными препаратами, поэтому правильному подбору препаратов и дозировок необходимо уделить должное влияние. Наибольшую опасность представляют комбинации пероральных сахароснижающих средств с хлорином и гидроксихлорином потому что при их использовании эффект гипогликемического лечения значительно усиливается, а значит необходима корректировка дозы препарата.

Наименее опасными сочетаниями являются сочетания азитромицина, интерферона бета, ивермектина, нитазоксанида, ремдесивира и рибавирина с антидиабетическими препаратами, потому что при использовании не были замечены нежелательные эффекты.

$* * *$

1. Mor A, Dekkers OM, Nielsen JS, Beck-Nielsen H, Sørensen HT, Thomsen RW. Impact of Glycemic Control on Risk of Infections in Patients With Type 2 Diabetes: A Population-Based Cohort Study. Am J Epidemiol. 2017;186(2):227-236. doi:10.1093/aje/kwx049

2. Fadini GP, Morieri ML, Longato E, Avogaro A. Prevalence and impact of diabetes among people infected with SARS-CoV-2. J Endocrinol Invest. 2020;43(6):867-869. doi:10.1007/s40618-020-01236-2

3. Holman N, Knighton P, Kar P, O'Keefe J, Curley M, Weaver A, et al. Risk factors for COVID-19-related mortality in people with type 1 and type 2 diabetes in England: a population-based cohort study. Lancet Diabetes Endocrinol. 2020;8(10):823-33. DOI: 10.1016/S2213-8587(20)30271-0

4. Jiang F, Deng L, Zhang L, Cai Y, Cheung CW, Xia Z. Review of the Clinical Characteristics of Coronavirus Disease 2019 (COVID-19). J Gen Intern Med. 2020;35(5):1545-1549. doi:10.1007/s11606020-05762-w

5. Hodge C, Marra F, Marzolini C, et al. Drug interactions: a review of the unseen danger of experimental COVID-19 therapies. J Antimicrob Chemother. 2020;75(12):3417-3424. doi:10.1093/jac/dkaa340

6. «Временные методические рекомендации «Профилактика, диагностика и лечение новой коронавирусной инфекции (COVID-19). Версия 10 (08.02.2021)», утвержденные Минздравом России, 2020г. http://www.consultant.ru/cons/cgi/online. - [Электронный ресурс] cgi? req $=$ doc $\&$ base $=$ LAW $\& n=347896 \&$ fld $=134 \& d s t=100001,0 \&$ rnd $=0.5124843473010268 \# 0662228716$ $425711 \backslash$

\title{
Лившиц Я.В., Каминская Л.А. \\ Гематологические и биохимические показатели крови у пожилых женщин с диагнозом сахарный диабет 2 типа на фоне лечения
}

ФГБОУ ВО Уральский государственный медицинский университет (Россия, Екатеринбург)

doi: 10.18411/lj-04-2021-52

\section{Аннотация}

Представлены результаты анализа гематологических и биохимических показателей крови 10 пожилых пациенток $(65,9 \pm 3,3)$ лет с сахарным диабетом 2 типа на фоне лечения. Уровень глюкозы натощак превышал диагностические критерии у 60 \%, показатель СОЭ у 40\% обследованных. Содержание глюкозы в крови связано с интенсивностью цитолиза гепатоцитов, положительная связь $(K=+0.62)$ с активностью АЛТ крови. Положительные значения коэффициентов парных корреляций выявляют зависимость возраст/ уровень моноцитов; эритроциты/ гемоглобин. Отрицательные связи: эритроциты/ тромбоциты $(K=-048)$; гемоглобин/СОЭ $(\mathrm{K}=-0,72)$, гемоглобин / тромбоциты $(K=-0,50)$ следует считать отражением у пациенток воспалительных процессов.

Ключевые слова: сахарный диабет 2 типа, пожилые, женщины, анализ крови, корреляции.

\section{Abstract}

The results of the analysis of hematological and biochemical blood parameters of 10 elderly patients $(65.9 \pm 3.3)$ years old with type 2 diabetes mellitus during treatment are 
presented. Fasting glucose levels exceeded diagnostic criteria in $60 \%$, ESR in $40 \%$ of those examined. The content of glucose in the blood is associated with the intensity of cytolysis of hepatocytes, a positive relationship $(\mathrm{K}=+0.62)$ with the activity of ALT in the blood. Positive values of the paired correlation coefficients reveal the age / monocyte level relationship; erythrocytes / hemoglobin. Negative relationships: erythrocytes / platelets $(\mathrm{K}=-$ 048); hemoglobin / ESR ( $\mathrm{K}=-0.72)$, hemoglobin / platelets $(\mathrm{K}=-0.50)$ should be considered a reflection of inflammatory processes in patients.

Key words: type 2 diabetes mellitus, elderly, women, blood test, correlations.

Сахарный диабет (СД) одно из наиболее распространенных эндокринных заболеваний. В мире насчитывается около 200 млн. больных диабетом, при этом почти 90\% из них страдают сахарным диабетом 2-го типа.[1]. Сахарный диабет 2 типа (СД2) метаболическое заболевание, характеризующееся хронической гипергликемией, развивающейся в результате нарушения взаимодействия инсулина с клетками тканей. В патогенезе СД2 рассматривают нарушения на трех уровнях. Первый: качественные нарушения секреции инсулина. Второй: инсулинорезистентность тканей, связанная с обусловленной генетически продукцией измененной молекулы инсулина; с уменьшением количества и синтезом неактивных рецепторов; с уменьшением числа транспортеров глюкозы на мембранах клеток. Третий: нарушение циркадного ритма, повышение продукции глюкозы ночью[6]. Цель исследования: Анализ гематологических и биохимических показателей крови у пожилых женщин с диагнозом сахарный диабет 2 типа на фоне лечения

\section{Материалы и методы исследования}

Проведен ретроспективный анализ историй болезни пациентов женского пола, находящихся на лечении в кардиологическом отделении МО «Новая больница» (г. Екатеринбург, Россия) Группа включения: возраст - 58-74 года, основной диагноз сахарный диабет второго типа (СД2). Группа исключения: пациенты этого отделения без диагноза СД2.Для обсуждения выбраны гематологические показатели и биохимические показатели анализов крови, полученные в биохимической лаборатории данной клиники. Для анализа использованы данные общего анализа крови (эритроциты, лейкоциты, тромбоциты, гемоглобин, моноциты, СОЭ) и биохимические показатели: уровень глюкозы, креатинина, активность фермента крови АЛТ. Статистический анализ выполнен в стандартной программе STATISTICA -2010. Конфликта интересов нет.

\section{Обсужнение результатов}

Проведено исследование гематологических и биохимических показателей крови пациенток с диагнозом диабет 2 типа. Возраст пациенток $(65,9 \pm 3,3)$, от 58 до 73 лет. Показатели представлены в табл.1.

Таблиия 1

Гематологические и биохимические показатели крови пациенток

\begin{tabular}{|c|c|c|c|}
\hline \multirow{2}{*}{ Обсуждаемые показатели } & \multicolumn{3}{|c|}{ Значения обсуждаемых показателей } \\
\hline & пациенты & интервалы & норма [7] \\
\hline лейкоциты $\cdot 10^{9} /$ л & $6,97 \pm 1,16$ & $5,2-8,2$ & $4-10$ \\
\hline эритроциты" $10^{12} / л$ & $4,31 \pm 0,26$ & $3,8-4,7$ & $3,8-5,2$ (>65 лет) \\
\hline гемоглобин (г/л) & $132,8 \pm 12,6$ & $114-164$ & 117-161(>65 лет) \\
\hline тромбоциты" $10^{9} / л$ & $274,9 \pm 48,2$ & $211-378$ & $150-400$ \\
\hline лимфоциты (\%) & $32,9 \pm 6,5$ & $20,5-43,2$ & $19-37$ \\
\hline моноциты $(\%)$ & $5,75 \pm 1,41$ & $2,7-7,5$ & $3-12$ \\
\hline СОЭ (мм/ч.) & $24,9 \pm 12,2$ & $10-46$ & 2 - 30 (>50 лет) \\
\hline билирубин (мкмоль/л) & $9,75 \pm 3,47$ & $4,57-19,82$ & $0-21$ \\
\hline глюкоза (ммоль/л) & $7,88 \pm 2,19$ & $4,9-12,04$ & $4,1-5,9$ \\
\hline креатинин (мкмоль/л) & $63,6 \pm 9.52$ & $60-82$ & 53-106 (>50 лет) \\
\hline АЛТ ( Ед/л) & $18,0 \pm 3,66$ & $11,8-23,6$ & $0-35$ \\
\hline
\end{tabular}


У большинства пациенток основные гематологические показатели крови находятся в пределах референсных значений, соответствующих возрастной категории и женскому полу. Отклонения значений (\% от общего числа) в сравнении с высшей границей референсных норм проанализированы отдельно и представлены на диаграмме (рис 1). Среди гематологических показателей выявлено отклонение числа лимфоцитов у $30 \%$, СОЭ - у 40 \% обследованных, что свидетельствовало о наличии воспалительного процесса в организме даже без видимых клинических проявлений. Уровень глюкозы (ммоль/л) натощак у 60\% пациенток превышал диагностические критерии СД2 (цельная капиллярная кровь $\geq 6,1$, венозная $\geq 7,0$ ) [4]. В исследовании общего анализа крови в зависимости от уровня глюкозы обнаружено повышение количества форменных элементов крови на фоне гипергликемии и увеличение времени седиментации эритроцитов [2].

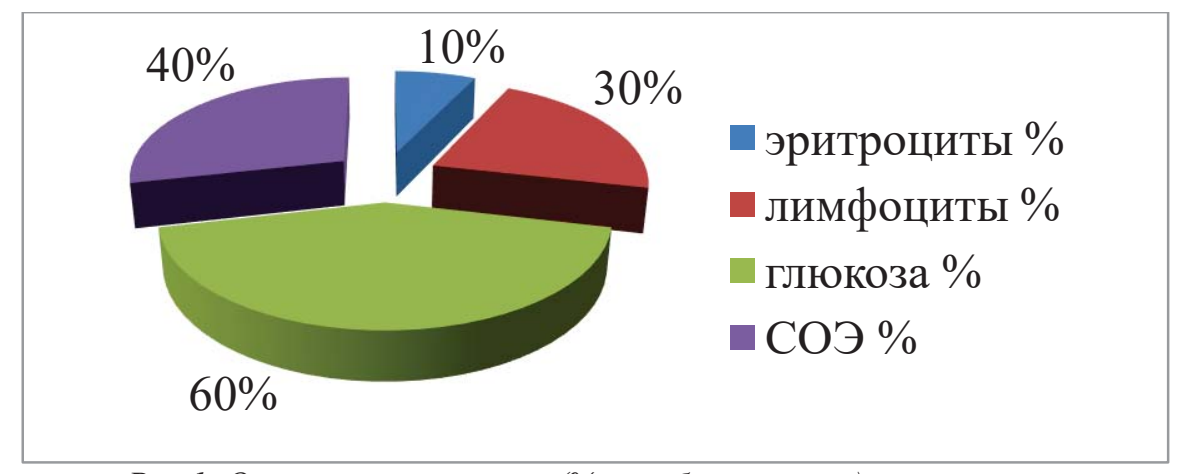

Рис.1. Отклонения значений (\% от общего числа) показателей

В исследовании по Нижегородской области для больных сахарным диабетом 2 типа были характерны высокие показатели общего числа лейкоцитов и СОЭ [5]. Типичными осложнениями сахарного диабета 2 типа являются нефро- и гепатопатии. Нормальный уровень креатинина у обследованных нами пациенток подтверждает отсутствие нарушений функции почек, а показатели активности АЛТ и содержания билирубина в крови говорят об отсутствии нарушений функций печени. Нами проведен корреляционный анализ методом парных корреляций, позволяющий выявить связи между показателями крови у пожилых пациенток с СД2 и предвидеть направление изменений (табл.2). Принимали во внимание значение коэффициента парной корреляции, если К>0,4.Несмотря на небольшую по численности группу, выявлены как положительные, так и отрицательные связи внутри гематологических показателей и между гематологическими и биохимическими показателями (табл. 2). Положительные значения и связи средней силы парных корреляций выявляют зависимость между уровнем эритроцитов и содержанием в них гемоглобина; между возрастом пациенток и уровнем моноцитов. Моноциты в тканях дифференцируются в органоспецифические макрофаги. Действие моноцитов как показателя воспаления может имеет связь с различными органами, в том числе и почками, через уровень креатинина крови (моноциты/ креатинин, К =+ 0,42).

Таблииа 2

Парные корреляцчии показателей крови

\begin{tabular}{|c|c|c|c|}
\hline Пары & К & Пары & К \\
\hline эритроциты/тромбоциты & $-0,48$ & возраст/моноциты & $+0,40$ \\
\hline гемоглобин/ тромбоциты & $-0,50$ & эритроциты/гемоглобин & $+0,62$ \\
\hline гемоглобин/СОЭ & $-0,72$ & глюкоза /АЛТ & $+0,62$ \\
\hline глюкоза/тромбоциты & $-0,44$ & АЛТ/ лимфоциты & $+0,43$ \\
\hline АЛТ/лейкоциты & $-0,45$ & \multirow{2}{*}{ моноциты/ креатинин } & $+0,42$ \\
\hline АЛТ/ тромбоциты & $-0,52$ & \\
\hline
\end{tabular}


Содержание глюкозы в крови связано с интенсивностью цитолиза гепатоцитов, что отражается в положительной связи с активностью АЛТ крови $(К=+0.62)$. У больных СД в зависимости от степени декомпенсации углеводного обмена отмечен цитолитический синдром: у больных с посредственной степенью компенсации углеводного обмена повышение АЛТ у 48,1\% обследованных, с субкомпенсацией - у $69,0 \%$ [3]. Отрицательные обратные связи при корреляции гематологических показателей у пожилых пациенток с СД 2 типа проявились в парах: гемоглобин/СОЭ $(K=-0,72)$, эритроциты/ тромбоциты $(K=-048)$; гемоглобин / тромбоциты $(K=-0,50)$; которые являются отражением воспалительных процессов у пациенток с СД 2 типа. Все пациенты получали квалифицированное и обоснованное лечение препаратами Метформином, Янувия, Глидиаб, Джардинс, обсуждение результатов которого не входило в задачи нашего исследования.

\section{Выводы}

Уровень глюкозы натощак превышал диагностические критерии у 60 \% обследованных пациенток, показатель СОЭ у 40\% на фоне остальных референсных значений гематологических и биохимических показателей. Содержание глюкозы в крови связано с интенсивностью цитолиза гепатоцитов, что отражается в положительной связи $(K=+0.62)$ с активностью АЛТ крови. Положительные значения коэффициентов парных корреляций выявляют зависимость между возрастом пациенток и уровнем моноцитов; между уровнем эритроцитов и содержанием в них гемоглобина. Отрицательные обратные связи, которые проявились в парах: эритроциты/ тромбоциты $(K=-048)$; гемоглобин/СОЭ $(\mathrm{K}=-0,72)$, гемоглобин /тромбоциты $(K=-0,50)$, следует считать отражением наличия воспалительных процессов.

$$
* * *
$$

1. Белоусова О.Н. Сиротина С.С. Якунченко Т.И. Жернакова Н.И Молекулярные и генетические механизмы патогенеза сахарного диабета 2 типа// Научные ведомости БелГУ. Сер. Медицина. Фармация. - 2015. -№16(213).-вып.31.-С.12-19.

2. Машина А, А., Черняева М. В. Параметры общего анализа крови в зависимости от уровня глюкозы// 2017. - сер.9.- вып.15.- С.114 -116.

3. Прозорова И.В., . Особенности клинико-биохимических различий у больных с сахарным диабетом различной степени компенсации/ И.В. Прозорова, Д.А. Шамиладзе. Н.В. Прозорова, и др.// Вестник Новгородского государственного университета им. Ярослава Мудрого.-2016.-№6(97).C.49-53.

4. РЦРЗ (Республиканский центр развития здравоохранения МЗ РК). Версия: Клинические протоколы МЗ PK - 2019. URL:https://diseases.medelement.com/disease/

5. Романова Е.Б., Сотова М.О. Гематологические и биохимические показатели крови больных сахарным диабетом второго типа, проживающих в Нижегородской области // Международный журнал прикладных и фундаментальных исследований. - 2015. - № 10-1. - С. 163-166; URL: https://applied-research.ru/ru/article/view?id=

6. Шуварова Е.А., Кива А. А., Маркво Л. И.. // Молодой ученый. — 2016. — № 26.2 (130.2). — С. 5052. —URL: https://moluch.ru/archive/130/36177/

7. Хеликс. Клинический и биохимический анализ крови - основные показатели. URL:https://helix.ru/kb/item/40-06.

Олейник Н.А., Козенко Т.Е.

Профилактика воспалительных осложнений после удаления нижних зубов мудрости с помощью фаготерапии

ФГБОУ ВО «Волгоградский государственный медииинский университет» Министерства здравоохранения Российской Федерации

(Россия, Волгоград)

doi: 10.18411/lj-04-2021-53

Аннотация

Возникновению местных осложнений гнойно-воспалительного генеза способствует ряд факторов, среди которых ведущее значение имеет эндогенная 